eISSN 2444-7986

DOI: https://doi.org/10.14201/orl201781.14832

Artículo de revisión

\title{
RESONANCIA MAGNÉTICA EN HIPOACUSIA Y VÉRTIGO
}

\section{Magnetic resonance in hearing loss and vertigo}

\author{
Manuel Ángel MARTÍN-PÉREZ; José Martín MARÍN-BALBÍN; Rodrigo BLANCO- \\ HERNÁNDEZ; Ignacio MARTÍN-GARCÍA; Roberto TABERNERO-RICO; Miguel \\ GONZALO-DOMÍNGUEZ
}

SACYL. Complejo Asistencial de Zamora. Servicio de Radiodiagnóstico. Zamora. España.

Correspondencia: martinperezma@gmail.com

Fecha de recepción: 25 de junio de 2016

Fecha de aceptación: 4 de julio de 2016

Fecha de publicación: 18 de julio de 2016

Fecha de publicación del fascículo: 1 de marzo de 2017

Conflicto de intereses: Los autores declaran no tener conflictos de intereses Imágenes: Los autores declaran haber obtenido las imágenes con el permiso de los pacientes

Política de derechos y autoarchivo: se permite el autoarchivo de la versión post-print (SHERPA/RoMEO)

Licencia CC BY-NC-ND. Licencia Creative Commons Atribución-NoComercial-SinDerivar 4.0 Internacional

๔C Universidad de Salamanca. Su comercialización está sujeta al permiso del editor

RESUMEN

PALABRAS CLAVE

SUMMARY
Introducción y objetivo: La hipoacusia y el síndrome vertiginoso representan una parte importante de la clínica otorrinolaringológica, siendo fundamental el papel que el radiólogo desempeña en su estudio diagnóstico. Los estudios mediante resonancia magnética (RM) son imprescindibles para orientar o dar el diagnostico de certeza en estos casos. Material y método: Tras realizar un análisis retrospectivo de 456 estudios de RM de pacientes que presentaban estos síntomas, realizamos una revisión por las principales patologías registradas que pueden ocasionar esta sintomatología. Resultados: Se clasifican en alteraciones vasculares y otras variantes, patología tumoral y patología malformativa e inflamatoria; además describimos los hallazgos más relevantes en RM y lo ilustramos con ejemplos recogidos en nuestro centro.

diagnóstico por imagen; vértigo; mareo; schwannoma; resonancia magnética; hipoacusia; neoplasias de fosa posterior diagnóstico

Introduction and objective: Hearing loss and vertiginous syndrome represent an important part of the otorhinolaryngology clinic. The role of the radiologist plays in their workup become fundamental. Studies using magnetic resonance imaging (MRI) are essential to guide or give the diagnosis in these cases. Method: After performing a retrospective analysis of $456 \mathrm{MRI}$ studies of patients with these symptoms, we conducted a review of the main pathologies recorded that can cause these symptoms. Results: We classify into vascular disorders and other variants, tumor pathology, malformations and inflammatory pathology; We also describe the most relevant findings on MRI and illustrated with examples of our center.

KEYWORDS diagnostic imaging; vertigo; dizziness; schwannoma; magnetic resonance imaging; hearing loss; posterior fossa neoplasms diagnosis 


\section{INTRODUCCIÓN}

La hipoacusia y el síndrome vertiginoso representan una parte importante de la clínica registrada en las consultas los servicios de otorrinolaringología (ORL) de cualquier hospital. Es en este contexto en el que el radiólogo cobra un importante papel diagnóstico a través de los estudios mediante resonancia magnética (RM) de oído interno y fosa posterior. Por esta razón fundamental es importante determinar su utilidad en la batería de pruebas complementarias para este tipo de patologías.

Con este trabajo se intenta reflejar el papel actual de la RM en los pacientes con hipoacusia o síndrome vertiginoso, además de ilustrar los hallazgos patológicos y variantes de la normalidad detectados mediante esta técnica.

\section{MATERIAL Y MÉTODO}

A partir de un análisis retrospectivo de 456 estudios consecutivos de RM, se realizó una descripción de la técnica y de los hallazgos patológicos por imagen. Las pruebas fueron realizadas en un equipo GE 1,5 T, empleando secuencias potenciadas en T1, T2, Difusión (DWI) y estudio 3D FIESTA de ambos oídos internos.El criterio de inclusión de los pacientes fue presentar clínica de hipoacusia, acúfeno o vértigo central o periférico. En la revisión, los pacientes fueron clasificados en dos grupos sintomáticos: uno con hipoacusia o acúfeno y otro con vértigo central o periférico. Con estos criterios se incluyeron 456 pacientes sintomáticos: 211 con clínica de hipoacusia neurosensorial o acúfeno y 245 con vértigo central o periférico, incluyendo otros síntomas inespecíficos como inestabilidad o mareo.

Del total de pacientes sintomáticos estudiados (456), se dividen e ilustran los estudios de los hallazgos patológicos, que supusieron el $17 \%$ del total (78 pacientes). Estos casos patológicos fueron desglosados en tres grupos: un grupo con alteraciones vasculares, bucles y otras variantes, que incluye 46 casos $(10 \%)$, otro grupo con patología tumoral en el contexto o no de neurofibromatosis (NF), tumores típi$\cos$ y atípicos del ángulo pontocerebeloso (APC), metástasis en fosa posterior y procesos intracraneales o del oído medio con repercusión sobre el laberinto membranoso, que incluye 25 casos $(5,5 \%)$ y un grupo final con patología malformativa e inflamatoria laberíntica, que incluye 7 casos $(1,5 \%)$. El resto de casos
(378 pacientes) fueron normales o no presentaron alteraciones relacionadas con el proceso de consulta.

\section{RESULTADOS \\ RECUERDO ANATÓMICO}

La RM permite establecer una detallada correlación de la anatomía del oído interno, identificando las distintas estructuras del laberinto membranoso: la cóclea, el vestíbulo y los canales semicirculares. (Figuras 1 y 2 ).

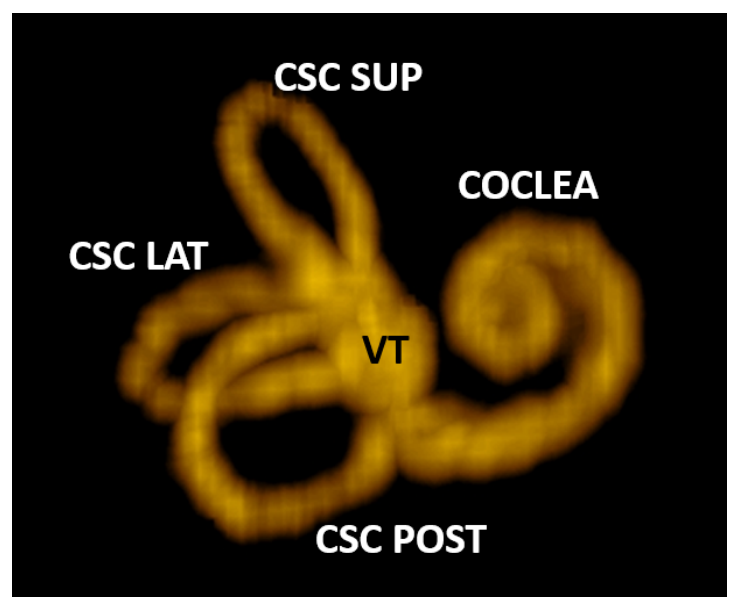

Figura 1. 3D FIESTA. Reconstrucción VR 3D. Anatomía del oído interno. Cóclea. VT: vestíbulo. CSCSUP: canal semicircular superior. CSCPOST: canal semicircular posterior. CSCLAT: canal semicircular lateral.

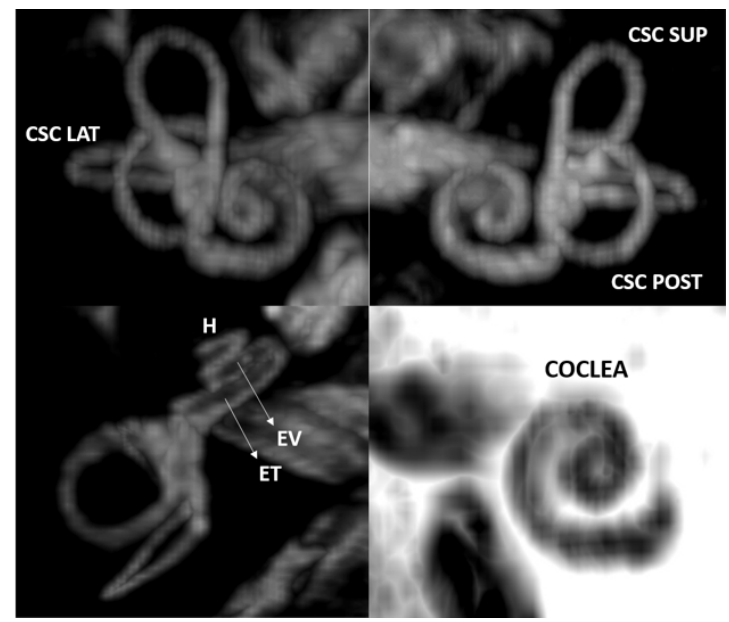

Figura 2. 3D FIESTA. Reconstrucción 2D MIP. Anatomía del oído interno. CSCLAT: canal semicircular lateral. CSCSUP: canal semicircular superior. CSCPOST: canal semicircular posterior. Identificamos en las espiras de la cóclea, su vértice; $\mathrm{H}$ : helicotrema. La escala timpánica $(E T)$, y la escala vestibular (EV). 
La cóclea es una estructura de forma espiral, dentro de la cual se aprecian tres canales paralelos: las escalas vestibular y timpánica, que contienen perilinfa y el conducto coclear, donde reside el órgano de Corti. En el conducto auditivo interno es posible identificar por separado los nervios del paquete acusticofacial. (Figuras 3 y 4 ).

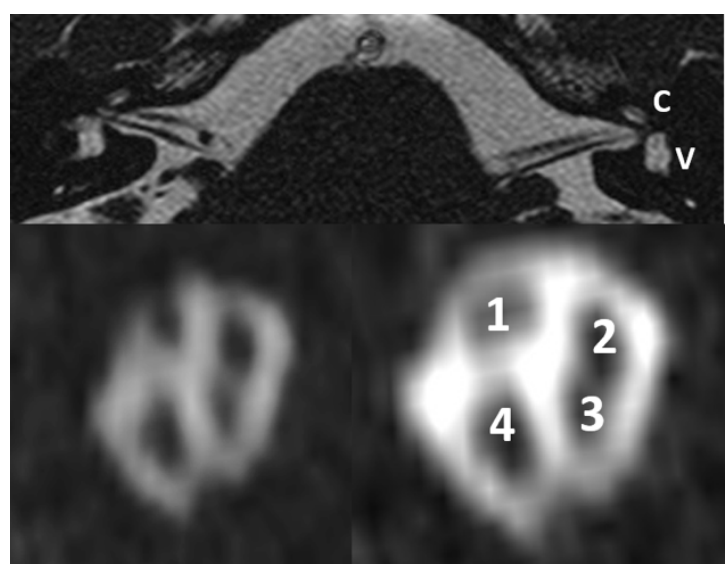

Figura 3. Imagen superior: 3D FIESTA en el plano axial de corte en poros acústicos, mostrando paquetes acusticofaciales, vestíbulos $(\mathrm{V})$ y cócleas $(\mathrm{C})$. Imágenes inferiores 3D FIESTA. Corte coronal oblicuo a través del CAI. Paquete acusticofacial. 1: nervio facial. 2: nervio vestibular superior. 3: nervio vestibular inferior. 4: nervio coclear.

PROTOCOLO DE ESTUdio CON RM DEL OÍDO INTERNO

Se resume en la tabla1.

Todos los pacientes fueron estudiados en equipo de RM Signa EXCITE 1.5T G.E.

Además de la exploración convencional de cráneo que incluyeron secuencias potenciadas en difusión (DWI), T2FLAIR y FRFSE, se realizaron secuencias específicas y centradas para estudio de oído interno: T2FRFSE, T1FSPGR y 3D FIESTA, que programadas siguiendo el eje de los conductos auditivos internos. Esta última es una secuencia rápida eco de gradiente con transformación de Fourier $3 D$, en Steady-State. Se empleó antena de alta resolución de cráneo phased-array de 8 canales. Los síntomas clínicos admitidos para estudio de pacientes incluyeron: vértigo, inestabilidad, hipoacusia y acúfenos. Posteriormente se procesaron las imágenes en consola, con reconstrucciones 2D MIP en varios planos y 3D Volume Rendering (VR).

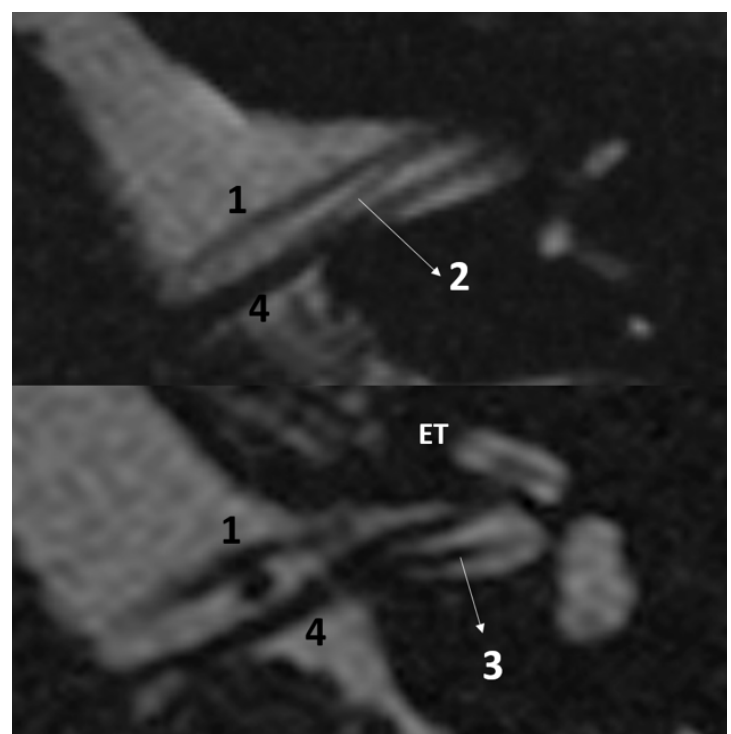

Figura 4. 3D FIESTA plano axial. 1: nervio facial. 2: nervio vestibular superior. 3: nervio vestibular inferior. 4: nervio vestíbulo-coclear. ET: escala timpánica.

Tabla 1. Protocolo de estudio con RM de oído interno.

\begin{tabular}{|c|c|c|c|c|c|c|c|c|}
\hline 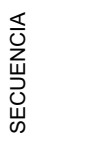 & 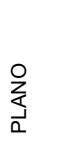 & $\begin{array}{l}\text { r } \\
\text { O } \\
\text { O } \\
\frac{1}{0}\end{array}$ & $\begin{array}{l}\frac{0}{U} \\
\frac{1}{0} \\
\omega \\
w\end{array}$ & $\stackrel{\mathscr{N}}{\vdash}$ & $\stackrel{\uplus}{\models}$ & రె & 离 & $\frac{\frac{N}{\underline{K}}}{\frac{K}{\Sigma}}$ \\
\hline \multicolumn{9}{|c|}{ PRECONTRASTE } \\
\hline $\begin{array}{l}\text { T2FLAI } \\
\mathrm{R}\end{array}$ & AXIAL & 4 & $\begin{array}{l}1 . \\
5\end{array}$ & $\begin{array}{l}80 \\
00\end{array}$ & $\begin{array}{l}14 \\
3\end{array}$ & $\begin{array}{l}24 X \\
24\end{array}$ & 2 & $\begin{array}{l}320 \times 2 \\
56\end{array}$ \\
\hline DWI & AXIAL & 4 & $\begin{array}{l}1 . \\
5\end{array}$ & $\begin{array}{l}80 \\
00\end{array}$ & 87 & $\begin{array}{l}24 X \\
24\end{array}$ & 1 & $\begin{array}{l}128 \times 1 \\
28\end{array}$ \\
\hline $\begin{array}{l}\text { T2FRF } \\
\text { SE }\end{array}$ & AXIAL & 4 & $\begin{array}{l}1 . \\
5\end{array}$ & $\begin{array}{l}32 \\
40\end{array}$ & 91 & $\begin{array}{l}24 X \\
24\end{array}$ & 2 & $\begin{array}{l}320 \times 2 \\
56\end{array}$ \\
\hline $\begin{array}{l}\text { 3DFIES } \\
\text { TA }\end{array}$ & AXIAL & $\begin{array}{l}0 . \\
8\end{array}$ & $\begin{array}{l}0 . \\
4\end{array}$ & 5.4 & $\begin{array}{l}1 . \\
5\end{array}$ & $\begin{array}{l}18 X \\
18\end{array}$ & 2 & $\begin{array}{l}320 \times 2 \\
56\end{array}$ \\
\hline $\begin{array}{l}\text { T2FRF } \\
\text { SE }\end{array}$ & $\begin{array}{l}\text { CORO } \\
\text { NAL }\end{array}$ & 3 & $\begin{array}{l}0 . \\
0\end{array}$ & $\begin{array}{l}34 \\
40\end{array}$ & $\begin{array}{l}12 \\
2\end{array}$ & $\begin{array}{l}18 X \\
18\end{array}$ & 4 & $\begin{array}{l}320 \times 2 \\
56\end{array}$ \\
\hline $\begin{array}{l}\text { T1FSP } \\
\text { GR }\end{array}$ & AXIAL & 2 & $\begin{array}{l}0 . \\
2\end{array}$ & $\begin{array}{l}25 \\
0\end{array}$ & 4 & $\begin{array}{l}18 X \\
18\end{array}$ & 4 & $\begin{array}{l}512 \times 2 \\
24\end{array}$ \\
\hline \multicolumn{9}{|c|}{ POSTCONTRASTE } \\
\hline $\begin{array}{l}\text { T1FSP } \\
\text { GR }\end{array}$ & AXIAL & 2 & $\begin{array}{l}0 . \\
2\end{array}$ & $\begin{array}{l}25 \\
0\end{array}$ & 4 & $\begin{array}{l}18 X \\
18\end{array}$ & 4 & $\begin{array}{l}512 \times 2 \\
24\end{array}$ \\
\hline $\begin{array}{l}\text { T1FSP } \\
\text { GR }\end{array}$ & $\begin{array}{l}\text { CORO } \\
\text { NAL }\end{array}$ & 2 & $\begin{array}{l}0 . \\
2\end{array}$ & $\begin{array}{l}25 \\
0\end{array}$ & 4 & $\begin{array}{l}18 X \\
18\end{array}$ & 4 & $\begin{array}{l}512 \times 2 \\
24\end{array}$ \\
\hline
\end{tabular}

\section{DISCUSIÓN}

CLASIFICACIÓN DE LOS HALLAZGOS SEGÚN SU LOCALIZACIÓN

Según su localización los hallazgos del APC pueden ser clasificados en diferentes grupos según indica la tabla 2. 
Tabla 2. Lesiones del APC según su localización.

\begin{tabular}{|l|l|}
\hline Localización & Lesión \\
\hline Cisternas & Quiste epidermoide \\
& Quiste dermoide \\
& Lipoma \\
& Quiste neuroénterico \\
& Quiste neuroepitelial \\
\hline Meninges & Meningioma \\
& Quiste aracnoideo \\
& Metástasis \\
\hline Arterias & Aneurisma \\
& Ectasias \\
\hline Nervios & Schwanomas del V-XII \\
\hline Base craneal & Granuloma de colesterol \\
& Paraganglioma \\
& Cordoma \\
& Tumores condrales \\
& Tumor del saco endolinfático \\
& Adenoma hipofisario \\
\hline Cerebelo-ventrículos & Glioma \\
& Linfoma \\
& Ependimoma \\
& Papiloma \\
& DNET \\
& Meduloblastoma \\
& Hemangioblastoma \\
\hline
\end{tabular}

CLASIFICACIÓN DE LOS HALLAZGOS SEGÚN SU COMPORTAMIENTO

Estos hallazgos también pueden ser clasificados según su comportamiento en las principales secuencias de RM, así como tras la administración de contraste paramagnético, como muestra la tabla 3 , donde además se describen los hallazgos más relevantes.

\section{PATOLOGÍA VASCULAR}

BUCLES VASCULARES

Consisten en cruces vasculares secundarios fundamentalmente por un trayecto redundante de la arteria cerebelosa anteroinferior (AICA) o de algunas pequeñas venas [1] (Figura 5). Estos bucles pueden producir compromiso de diferentes pares craneales (PC), principalmente del VIII PC [2]. Aunque en unos casos puede tratarse de un hallazgo incidental, también pueden ser causa de acúfenos o de vértigo, aunque se han publicado artículos que no han demostrado la relación entre el cruce vascular y algunos síntomas como los acúfenos [3].

Tabla 3. Comportamiento en RM de los hallazgos del APC.

\begin{tabular}{|c|c|c|c|c|}
\hline Lesión & Señal en T1WI & Señal en T2WI & Captación & Hallazgos \\
\hline Glioma & Hipointenso & Hiperintenso & Variable & Emerge del tronco del encéfalo. \\
\hline $\begin{array}{l}\text { Papiloma de plexos } \\
\text { coroideos }\end{array}$ & Hipointenso & Hiperintenso & Intenso & Se extiende desde el foramen de Luschcka. \\
\hline Linfoma & Hipointenso & Hiperintenso & Sí & Edema. Contexto de inmunodeficiencia. \\
\hline Hemangioblastoma & Hipointenso & Hiperintenso & Intenso & $\begin{array}{l}\text { Posible componente quístico. Enfermedad de } \\
\text { Von Hipple-Lindau. }\end{array}$ \\
\hline Ependimoma & Hipointenso & Hiperintenso & Sí & Irregular y heterogéneo. \\
\hline Meduloblastoma & Hipointenso & Hiperintenso & Sí & Nace del hemisferio cerebeloso. \\
\hline DNET & Hipointenso & Hiperintenso & Sí & Componente quístico. Erosión ósea. \\
\hline Quiste epidermoide & Hipointenso & Hiperintenso & No & Hiperintenso en DWI. \\
\hline Tumor dermoide & Hiperintenso & Hipointenso & No & Grasa y calcificaciones. Niveles liquido-grasa. \\
\hline Quiste aracnoideo & Hipointenso & Hiperintenso & No & Hipointenso en DWI. Isointenso con el LCR. \\
\hline Lipoma & Hiperintenso & $\begin{array}{l}\text { Isointenso con } \\
\text { la grasa }\end{array}$ & No & $\begin{array}{l}\text { Mismo comportamiento que la grasa subcutá- } \\
\text { nea en todas las secuencias. }\end{array}$ \\
\hline Schwanoma & Hipointenso & Hiperintenso & Sí & Sigue el curso anatómico del nervio. \\
\hline Aneurisma & Hipointenso & Hipointenso & Variable & $\begin{array}{l}\text { Lesión hipointensa bien definida en imágenes } \\
\text { potenciadas en } \mathrm{T} 2 \text {. }\end{array}$ \\
\hline Melanoma & Hiperintenso & Variable & Sí & $\begin{array}{l}\text { Lesión hiperintenso en imágenes potenciadas } \\
\text { en T1. }\end{array}$ \\
\hline Sarcoidosis & Hipointenso & Variable & Sí & $\begin{array}{l}\text { Preferentemente hipointensa en imágenes po- } \\
\text { tenciadas en T2. }\end{array}$ \\
\hline $\begin{array}{l}\text { Granuloma de coles- } \\
\text { terol }\end{array}$ & Hiperintenso & Hiperintenso & No & Anillo hipointenso en T1 y T2. \\
\hline Paraganglioma & Hipointenso & Hiperintenso & Sí & Apariencia en sal y pimienta \\
\hline Tumor condral & Hipointenso & Hiperintenso & Variable & Se origina de una sincondrosis. \\
\hline Cordoma & Hipointenso & Hiperintenso & Sí & Septos intratumorales. \\
\hline $\begin{array}{l}\text { Tumor del saco endo- } \\
\text { linfático }\end{array}$ & Variable & Hiperintenso & Sí & $\begin{array}{l}\text { Presencia de quistes hiperintensos en T1 y } \\
\text { T2. }\end{array}$ \\
\hline Petrositis apical & Hipointenso & Hiperintenso & Sí & Historia de otitis media. \\
\hline
\end{tabular}




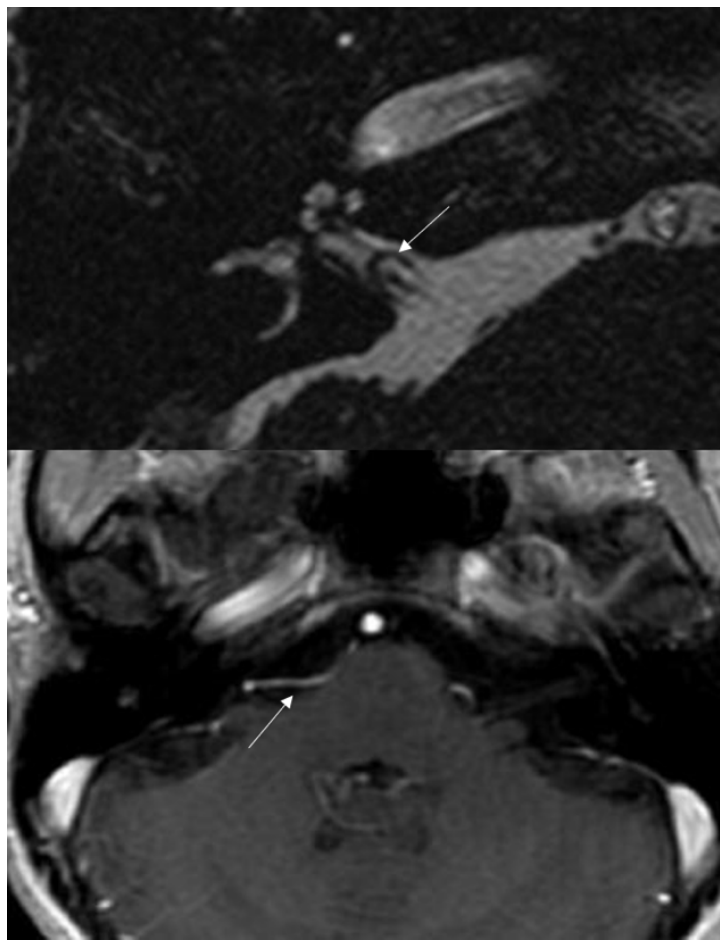

Figura 5. Bucle vascular producido por un trayecto redundante de la arteria cerebelosa anteroinferior (AICA) que no produce compromiso de los nervios del paquete acusticofacial en el interior del CAI derecho, como hallazgo incidental.

\section{MEGAGOLFO DE LA VENA YUGULAR}

La posición y el tamaño del golfo yugular son muy variables [4]. El golfo de la yugular alto es una variante de la normalidad que se considera cuando su margen se extiende hasta la superficie inferior del anillo óseo, protruyendo en el oído medio o en la espira basal de la cóclea. Si el golfo de la yugular presenta un aumento de su diámetro transversal se denomina megagolfo, independientemente de su posición [5]. En la mayoría de los casos, los pacientes permanecen asintomáticos, pero en otros casos pueden presentar diferente sintomatología dependiendo de la localización [6]

\section{DIVERTÍCULO DEL BULBO YUGULAR}

Es poco frecuente [7]. Se trata de una protrusión del bulbo yugular superior y medial al agujero yugular. En esta posición, el divertículo se relaciona directamente con la pared posterior del conducto auditivo interno (CAl). La invasión del CAl puede contribuir al déficit neurosensorial de la audición y otros síntomas [5], sin que se detecte en la otoscopia ya que puede no llegar hasta el oído medio [8]. Es fundamental un diagnóstico radiológico para evitar otras pruebas innecesarias [7].
PARAGANGLIOMA O GLOMUS YUGULAR

Se trata del tumor más frecuente del agujero yugular [9]. Deriva de los cuerpos glómicos, que están formados por células quimiorreceptoras presentes en el foramen yugular a lo largo del nervio vago. Estos tumores son benignos, pero localmente agresivos, que pueden destruir el peñasco y llegar a invadir el APC $[10,11]$. En RM se aprecia una masa de partes blandas hipervascularizada, con vacíos de señal serpentiformes o puntiformes producidos por los vasos sanguíneos con elevado flujo. Además, las hemorragias focales intratumorales con metahemoglobina aparecen como focos hiperintensos en secuencias T1WI, produciendo una característica apariencia en «sal y pimienta». Este tumor presenta un intenso realce tras la administración de contraste [11] (Figura 6).

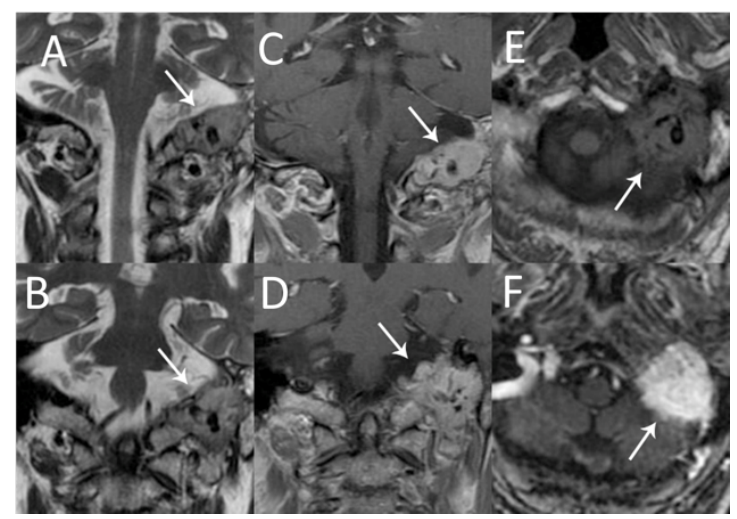

Figura 6. Secuencias potenciadas en T2 (plano coronal A y B) y T1 (plano axial E) y tras la administración de gadolinio (plano coronal C y D y axial F). Ver el intenso realce, de forma homogénea, con focos de hiposeñal. Se visualiza masa que rodea el bulbo yugular, ligeramente hiperintensa, y con focos de ausencia de señal de carácter vascular, en paciente con acúfeno en oído izquierdo. Apariencia en sal y pimienta. Diagnóstico: glomus yugular.

\section{ANGIOMA VENOSO}

También conocidos como Anomalías del Desarrollo Venoso, son variantes congénitas del drenaje venoso normal. Histológicamente están limitadas a las estructuras venosas, sin la participación de los capilares o arterias [12, 13]. Pueden presentar intensidad de señal variable dependiendo de su tamaño y flujo, apreciando vacío de señal en T1WI y T2WI. Tras la administración de contraste presentan un intenso realce apreciando una apariencia de paraguas invertido con las venas medulares prominentes 
(«cabeza de medusa» y una única vena colectora transcortical [14]. Suelen localizarse cerca de los ventrículos, si bien también pueden aparecer en el cerebelo, pudiendo producir cierto efecto de masa en el APC [14]. Suelen ser hallazgos casuales en estudios de RM con contraste, en pacientes asintomáticos o con síntomas no relacionados con estas anomalías [13] (Figura 7).

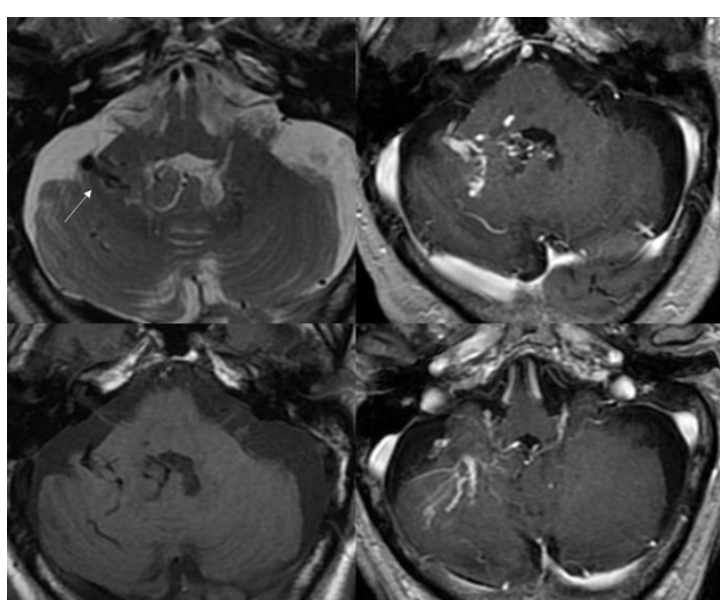

Figura 7. T2WI (arriba izquierda), T1WI (abajo izquierda) y T1 tras contraste (imágenes de la derecha). Anomalía venosa del desarrollo en flóculo derecho del cerebelo. Véase la confluencia de venas en forma de cabeza de medusa y la vena colectora hacia el APC.

\section{CAVERNOMA}

Es una malformación del desarrollo vascular, normalmente pequeña y multilobulada, con una morfología típica en "frambuesa». La hemorragia es una complicación común, pudiendo existir diferentes fases evolutivas [15, 16]. Se consideran angiomas venosos histológicamente mixtos [14].

\section{MALFORMACIONES VASCULARES}

Existen otras malformaciones vasculares localizadas en el agujero yugular [4] o fuera de éste que pueden producir sintomatología, como por ejemplo malformaciones arteriovenosas, fistulas durales, etc. $[17,18]$.

\section{ANEURISMAS DEL APC}

Generalmente se debe a la dilatación focal de la pared de la arteria cerebelosa posteroinferior (PICA), la arteria vertebral o la arteria cerebelosa anteroinferior (AICA). Los aneurismas del APC representan aproximadamente el $1 \%$ de las masas localizadas en este nivel [9].
También se han registrado casos en los que una dilatación aneurismática de la arteria carótida interna a nivel del conducto carotídeo se presenta como una masa pulsátil en el oído medio [19]. La RM se considera una técnica especialmente útil para el diagnóstico de sospecha de un aneurisma de estas características, así como para el seguimiento de su tratamiento tras oclusión endovascular [20].

Los aneurismas que presentan un alto flujo se aprecian como masas ovaladas o redondeadas sin ninguna señal, debido al elevado flujo. Una extrema baja intensidad de señal en T2WI es muy sugerente de este tipo de hallazgos. Cuando un aneurisma está trombosado, presenta una alta intensidad de señal en T1WI debido a la metahemoglobina; aunque es un hallazgo muy sugestivo la intensidad de señal es variable. El aumento del efecto masa puede observarse en la formación del trombo, lo que simula un schwannoma [11].

\section{HEMATOMA CEREBELOSO ANTIGUO}

Los hematomas antiguos, como en otras regiones del sistema nervioso central, pueden observarse con un área central hipointensa en todas las secuencias de pulso relacionada con el depósito de degeneración hemática de larga evolución, soliendo presentar también un anillo hemosiderótico completo, con el mismo significado [21].

\section{TROMBOSIS DEL SENO TRANSVERSO}

Es a menudo difícil de diagnosticar debido a que presenta un amplio espectro de manifestaciones clínicas inespecíficas, como hipertensión intracraneal, signos de focalidad neurológica, alteración del nivel de conciencia y trastornos mentales [22]. Puede ser difícil de diferenciar de la hipoplasia del seno transverso, en el caso de la trombosis se aprecia un defecto de llenado del seno transverso, que como en nuestro caso puede asociar isquemia con transformación hemorrágica temporal [22].

\section{ICTUS VERTEBROBASILAR}

Los accidentes cerebrovasculares (ACV) presentan un diagnóstico clínico inexacto en el 15$20 \%$ de los casos [14], en ocasiones manifestándose como inestabilidad y vértigo de instauración brusca. La oclusión aguda del sistema arterial vertebrobasilar supone el $20 \%$ del total de los ACV [23] y presenta una alta mortalidad que llega al $80 \%-90 \%$ en los pacientes sin repermeabilización. Por esta razón es importante realizar un diagnóstico en la fase precoz 
para lo cual son especialmente útiles las secuencias de difusión (DWI) [24, 25]. Aunque el territorio arterial más frecuentemente afectado en un paciente con síndrome vertiginoso brusco es el vertebrobasilar (Figura 8), también puede aparecer esta clínica secundaria a isquemia en otros territorios vasculares, o en el contexto de afectación por isquemia en distintos territorios, secundaria a un embolismo de origen cardiaco.

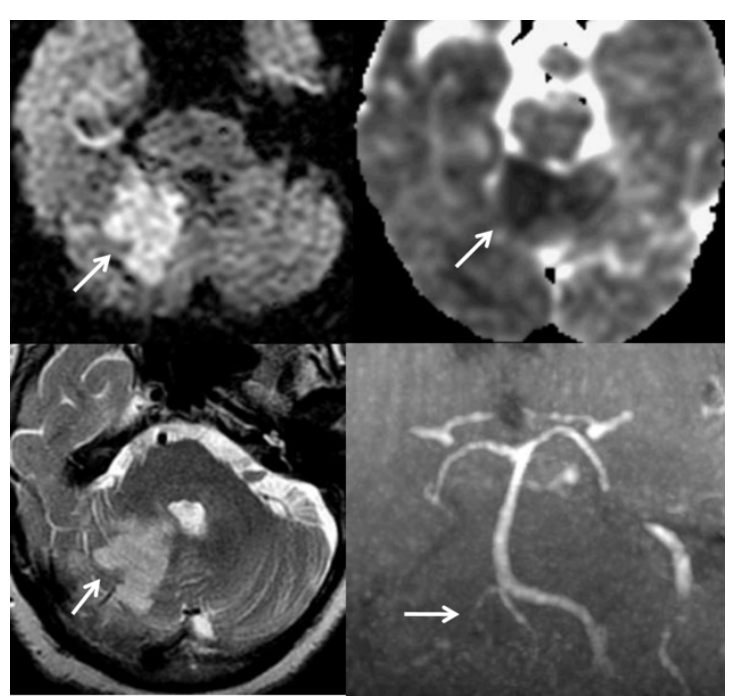

Figura 8. Extenso ictus vertebrobasilar, con afectación posterosuperior y medial del hemisferio cerebeloso derecho, y ramas de ACP (no mostrado). Ver imágenes de arriba, con hiperseñal en difusión (DWI) y restricción en cociente de difusión aparente (ADC), que denotan carácter agudo. Secuencias potenciadas en T2 (abajo izquierda) y reconstrucción coronal de estudio 3D TOF, que muestra trombosis de arteria vertebral ipsilateral.

\section{OTRAS VARIANTES}

Existen casos en los que una prominencia del ganglio de Gasser a nivel temporal produce un abombamiento sobre la porción craneal del APC y la base del CAI. Otro hallazgo casual puede ser la presencia de gotas grasas en el espacio subaracnoideo, que apreciaremos como focos puntiformes marcadamente hiperintensos en secuencias potenciadas en T1.

\section{PATOLOGÍA TUMORAL}

\section{TUMORES EPENDIMARIOS}

El lugar de origen de estas neoplasias varía según la edad, siendo más frecuente la localización intracraneal infratentorial en la infancia y la localización espinal en el adulto.

La clasificación de la OMS divide a los tumores ependimarios en grado I (ependimoma mixopapilar y subependimoma), grado II (ependimoma) y grado

III (ependimoma anaplásico) [26].

Los subependimomas son tumores raros y normalmente se encuentra en las regiones subependimales de los ventrículos. Los pacientes suelen presentar síntomas de progresión lenta y en ocasiones los tumores son descubiertos incidentalmente en la autopsia. La edad típica de presentación es la quinta o sexta década de la vida [27].

Los ependimomas presentan bordes irregulares que pueden invadir el parénquima cerebeloso. Son hipointensos en T1WI e hiperintensos en T2WI y realzan de manera irregular tras la administración de contraste. Son marcadamente heterogéneos debido a la presencia de calcificaciones, hemorragias, formaciones quísticas o necrosis [11].

\section{MEduloblastoma}

Es el tumor maligno más común del sistema nervioso central en edad pediátrica y el tumor primario más común de la fosa posterior en niños, localizándose principalmente a nivel del vermis cerebeloso [28], siendo la localización en el APC poco frecuente [29]. Se trata de un tumor altamente agresivo (grado IV de la OMS) [30]. Es más frecuente en varones, por lo general menores de 10 años. Aunque es mucho menos común, la enfermedad también puede ocurrir en adultos, por lo general en la tercera y cuarta década de la vida [28]. La clínica es rápidamente progresiva. En la RM, estos tumores son hipointensos en T1WI e iso o hiperintensos en T2WI, pudiendo presentar formaciones quísticas o necrosis. Realza tras la administración de contraste [11].

\section{QUISTE ARACNOIDEO}

Son cúmulos benignos de origen congénito de líquido cefalorraquídeo que se localizan en áreas donde existe aracnoides; el $50 \%$ de los mismos en la cisura de Silvio. Llegan a representar el $1 \%$ de todos los procesos expansivos intracraneales no traumáticos. La sintomatología depende de su tamaño y localización. En su evolución pueden comprimir el parénquima circundante y obstruir la circulación del líquido cefalorraquídeo provocando hidrocefalia o hipertensión intracraneal [31]. Tienen bordes bien definidos y forma redondeada (Figura 9a), desplazan a las estructuras neurovasculares y erosionan el hueso adyacente. No presentan calcificaciones o realce. Tienen la misma señal que el LCR, y son hiperintensos en secuencias T2WI e hipointensos en T1WI, pudiéndose confundir con quistes epidermoides [11]. 


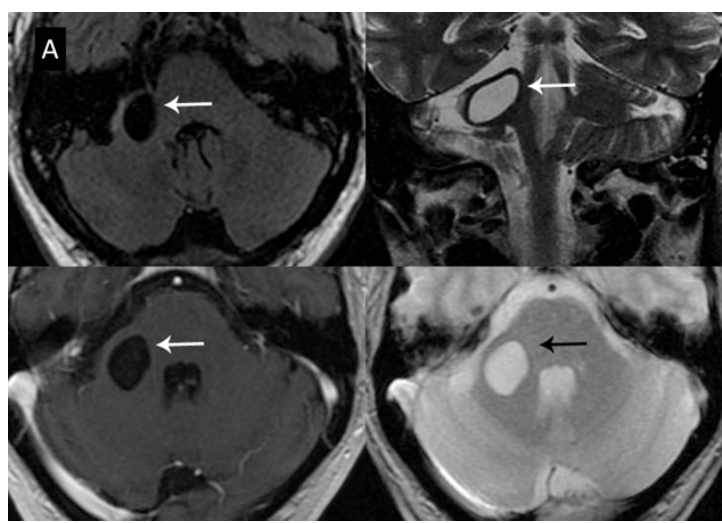

Figura 9a. Tumoración ovalada en APC y pedúnculo cerebeloso medio derecho, hiperintenso en secuencias potenciadas en T2FSE y GRE T2 (imágenes de la derecha), con intensidad de señal igual al LCR en secuencia potenciada en FLAIR (arriba izquierda). No realce tras gadolinio endovenoso (abajo izquierda).

\section{TUMOR DERMOIDE}

Son quistes de inclusión congénitos: las secreciones y los debris epiteliales descamados producen una expansión lenta, pudiéndose romper y producir morbilidad/mortalidad significativa [14]. Los quistes dermoides se encuentran a menudo en la fontanela anterior y la región occipital de los niños; una localización excepcional es el espacio extradural de la fosa posterior [32]. Al tener elementos de todas las capas de la piel puede contener pelo, grasa, glándulas sebáceas y sudoríparas, además de epitelio escamoso. Presentan una elevada intensidad de señal en T1WI debido a su conte- nido graso. Es muy sugestivo el nivel de líquido/grasa y pueden presentar calcificaciones [11] (Figura 9b).

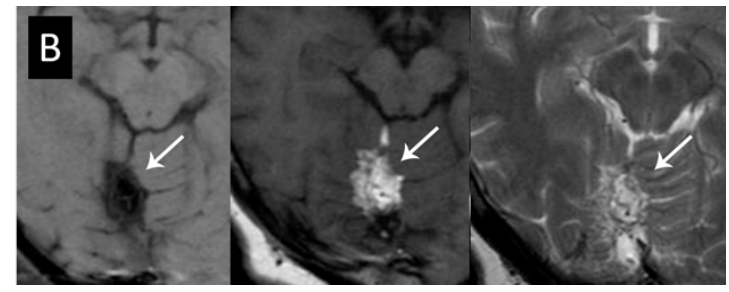

Figura 9b. Tumor dermoide en espacio subaracnoideo y cisternal de fosa posterior. Pérdida de señal en secuencia potenciada en T1 con supresión grasa. Hiperseñal por alto contenido lipídico de la tumoración, en secuencias potenciadas en T1 y T2 sin saturación grasa.

\section{GRANULOMA DE COLESTEROL}

Se produce como consecuencia de una reacción inflamatoria por la presencia de cristales de colesterol [33], comportándose como una masa expansiva que puede localizarse en el vértice del peñasco, aislando a las celdillas aéreas de éste del oído medio, y provocando un edema que da lugar a hemorragias recurrentes. Se trata del hallazgo más frecuente detectado en el vértice del peñasco, siendo menos frecuente que el granuloma de colesterol de la mastoides y oído medio [9]. Se trata de una tumoración hiperintensa en todas las secuencias de pulso [34], con un fino borde de baja intensidad de señal en T1WI y T2WI que se corresponde con la cortical del hueso expandido y el depósito de hemosiderina [11] (Figura 9c).

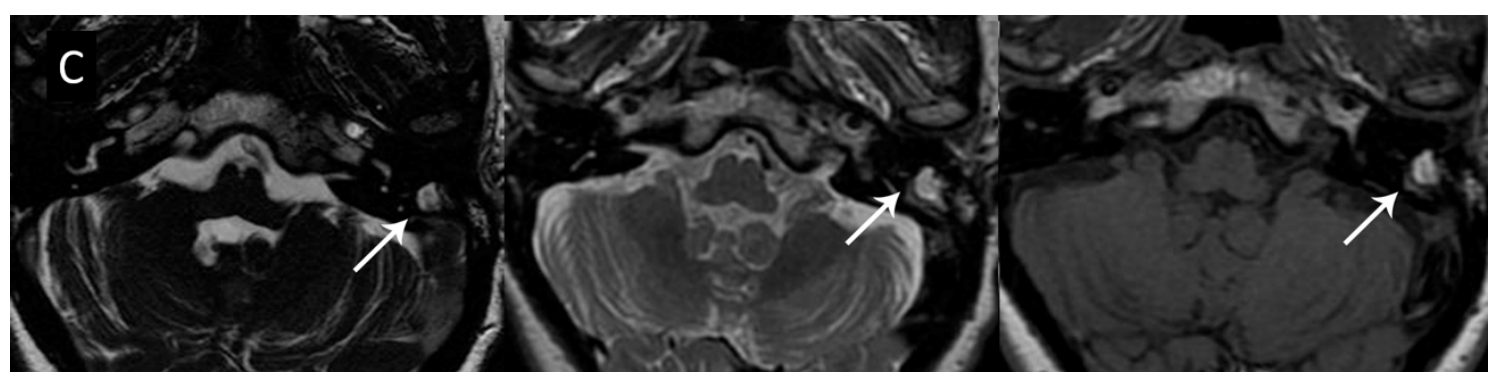

Figura 9c. Tumor hiperintenso en todas las secuencias de pulso (3D FIESTA, T2 y T1 respectivamente). Corresponde con un granuloma de colesterol del vértice del peñasco izquierdo.

\section{QUISTE EPIDERMOIDE}

Son quistes de inclusión no neoplásicos, suponiendo el $1 \%$ de todos los tumores intracraneales y la tercera masa en frecuencia en el APC y CAI [14]. Además de esta localización, la segunda en frecuencia es el cávum de Meckel
[35]. Puede tener características de intensidad de señal similar a las de LCR en todas las secuencias de pulso, lo que hace difícil distinguir estos tumores de quistes aracnoideos. La DWI ayuda a diferenciarlos de quistes aracnoideos, ya que el coeficiente de difusión aparente 
$(A D C)$ de tumores epidermoides es menor al del LCR [35]. (Figura 9d).

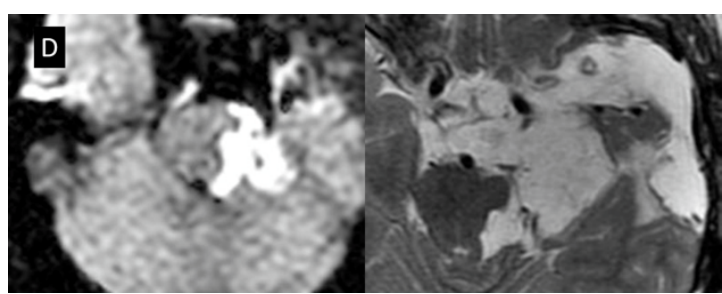

Figura 9d. Cuadro de inestabilidad de larga evolución. Tumoración de distribución geográfica, insinuante, poco delimitada, pero no infiltrante, que se distribuye a nivel cisternal, con efecto de masa sobre las estructuras con las que se relaciona. Características típicas en imagen del quiste epidermoide, con alta señal en difusión y T2. En este caso presenta gran extensión, hasta la cisterna supraselar, suelo del III ventrículo y APC izqdo.

\section{Colesteatoma}

Ha sido definido como «bola de piel en el sitio equivocado», debido a que se forma por la invasión del epitelio del conducto auditivo externo a través de una perforación timpánica, generalmente en la pars tensa, que se comporta como una neoformación expansiva [9]. Aunque se trata de un proceso benigno, produce erosión del hueso circundante y el hecho de que su crecimiento sea ilimitado puede causar complicaciones intracraneales potencialmente graves [36]. En la literatura científica existen múltiples artículos que describen graves complicaciones, incluso la muerte, secundarias a colesteatomas gigantes y su invasión de la fosa posterior [36].

En RM se aprecia como una masa hipointensa en T1WI e hiperintensa en T2WI, con bordes que realzan tras la administración de contraste. La destrucción ósea se valora con dificultad mediante RM [9, 36]. Debido a su composición, la difusión del agua se encuentra dificultada, lo que confiere especial utilidad a las secuencias DWI; tanto para el diagnóstico de pequeñas tumoraciones, como para el seguimiento y sospecha de recurrencia (Figura 10).

NEURINOMA O SCHWANNOMA DEL VIII PAR Y OTROS

Son tumores benignos de lento crecimiento que derivan de las células de Schwann que envuelven el VIII PC (nervio cocleovestibular) [37]. Es la masa más frecuente en el APC y CAl. Además, es la segunda neoplasia extraaxial más frecuente en adultos y una de las principales causas de hipoacusia neurosensorial unilateral [9]. Aunque los neurinomas vestibulares representan el 95\% de los schwannomas intracraneales, también pueden desarrollarse en los otros PC del APC, especialmente en el nervio trigémino y facial, además de los IX y XII PC [11]. Se aprecia como una masa focal hipointensa en T1WI e hiperintensa en $\mathrm{T} 2 \mathrm{Wl}$, que presenta un intenso realce tras la administración de contraste [9] (Figuras 11 a y b).

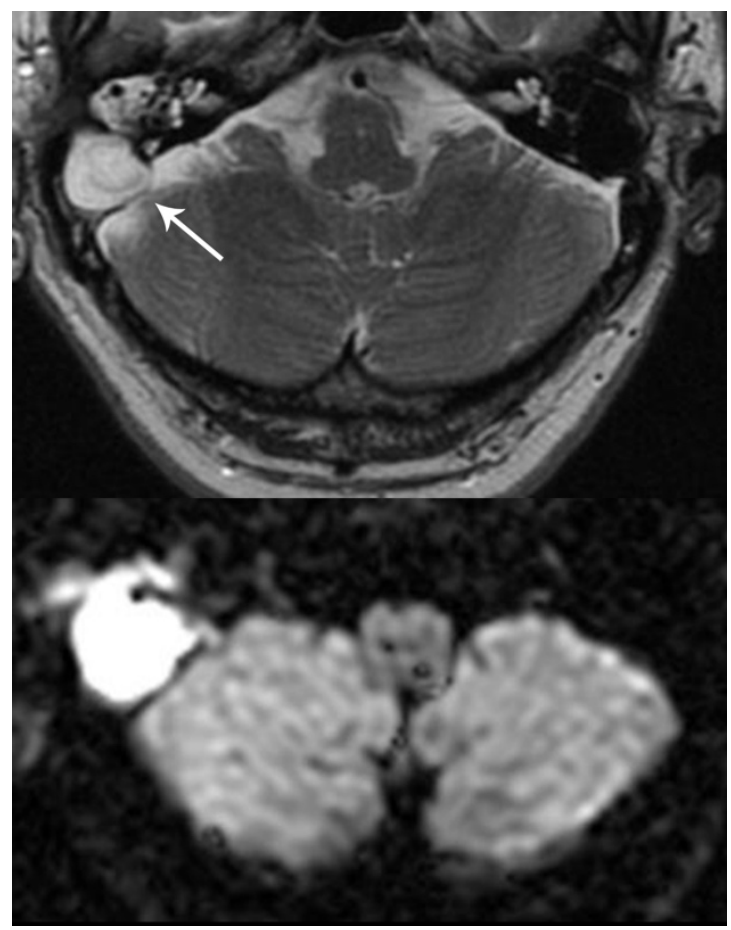

Figura 10. Referido por sordera mixta, de transmisión y neurosensorial, con inestabilidad, por afectación de los conductos semicirculares lateral y posterior. Secuencias potenciadas en T2 y DWI. Marcada hiperseñal por componentes queratínicos. Colesteatoma.

\section{MENINGIOMA DEL APC}

Es una neoplasia benigna, no encapsulada, que deriva de células de la aracnoides asociada a la duramadre de la cisterna del APC y CAI [9]. Es la segunda neoplasia más frecuente del APC, y junto con el neurinoma del VIII PC representan aproximadamente el $85 \%$ al $90 \%$ de todos los tumores a este nivel [11]. Además, puede asociarse a otros tumores en esta localización, siendo la combinación más frecuente con el glioma en los pacientes sin neurofibromatosis, o más raramente con el neurinoma [38]. Se aprecia como una masa hipointensa en T1WI, que realza de manera intensa y uniforme tras la administración de contraste [9] (Figura 12). 


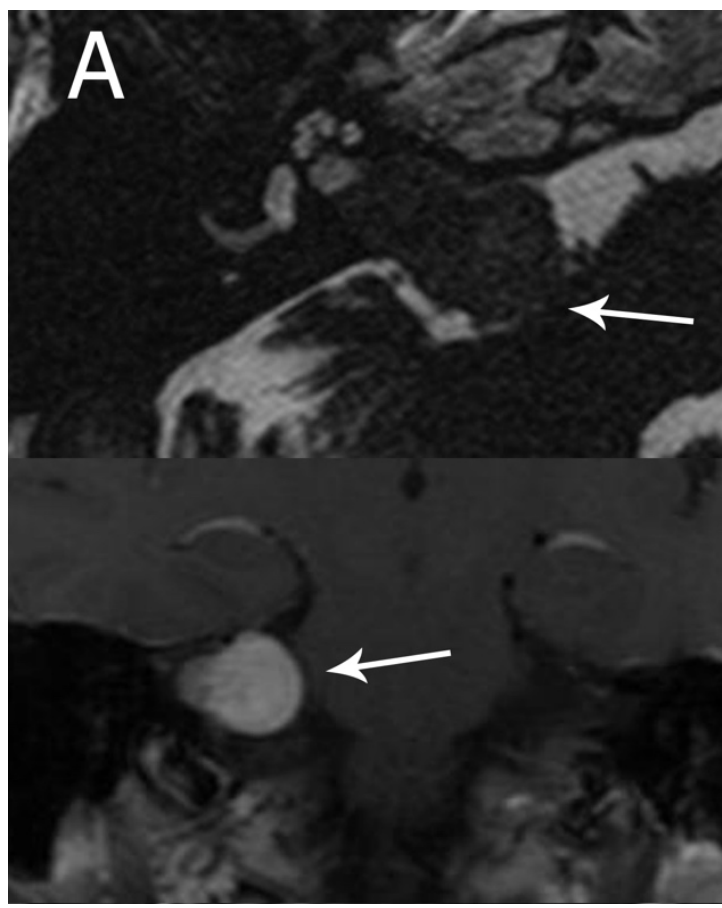

Figura 11a. Neurinoma del VIII, de localización intracanalicular (secuencia 3D FIESTA y T1 + C), con dilatación del mismo hasta el poro acústico y gran componente que ocupa el APC derecho. Realce homogéneo tras gadolinio.
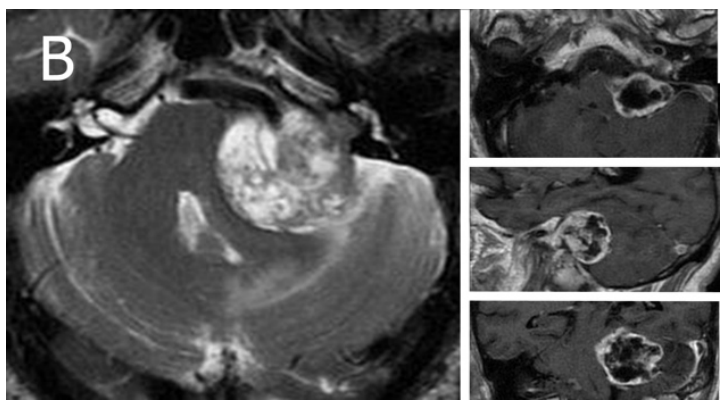

Figura 11b. T2WI (izquierda) y T1 tras contraste en los 3 planos del espacio (derecha). Aumento de tamaño, degeneración quística y realce heterogéneo de schwannoma del VIII par conocido tratado con radioterapia estereotáxica, ya que el paciente declinó el tratamiento quirúrgico. Evolucionó a cuadro de pérdida progresiva de audición, alteraciones del equilibrio y otalgia. Secuencias tras gadolinio donde se aprecia la captación heterogénea, fundamentalmente periférica.

\section{LINFOMA}

El linfoma primario es poco común en el sistema nervioso central [39]. Se puede observar en la fosa craneal posterior, incluyendo el APC [11]. En el estudio con RM no presentan características especificas pudiéndose confundir con otros tumores del APC. Sin embargo, el efecto de masa y el edema suelen estar presentes. Estos hallazgos asociados en el contexto de un paciente inmunocomprometido deben hacernos sospechar linfoma [11] (Figura 13a).

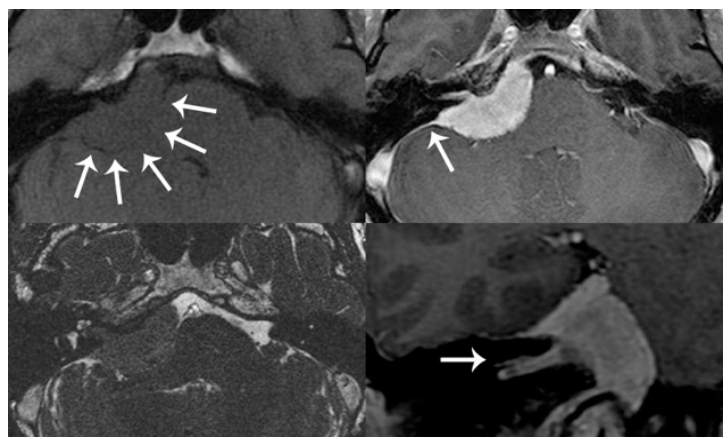

Figura 12. T1WI y 3D FIESTA (izquierda) y T1WI tras contraste endovenoso en los planos axial y coronal. Masa extraaxial que ocupa el APC derecho extendiéndose al conducto auditivo interno. Realce precoz y homogéneo, con cola dural. Meningioma.

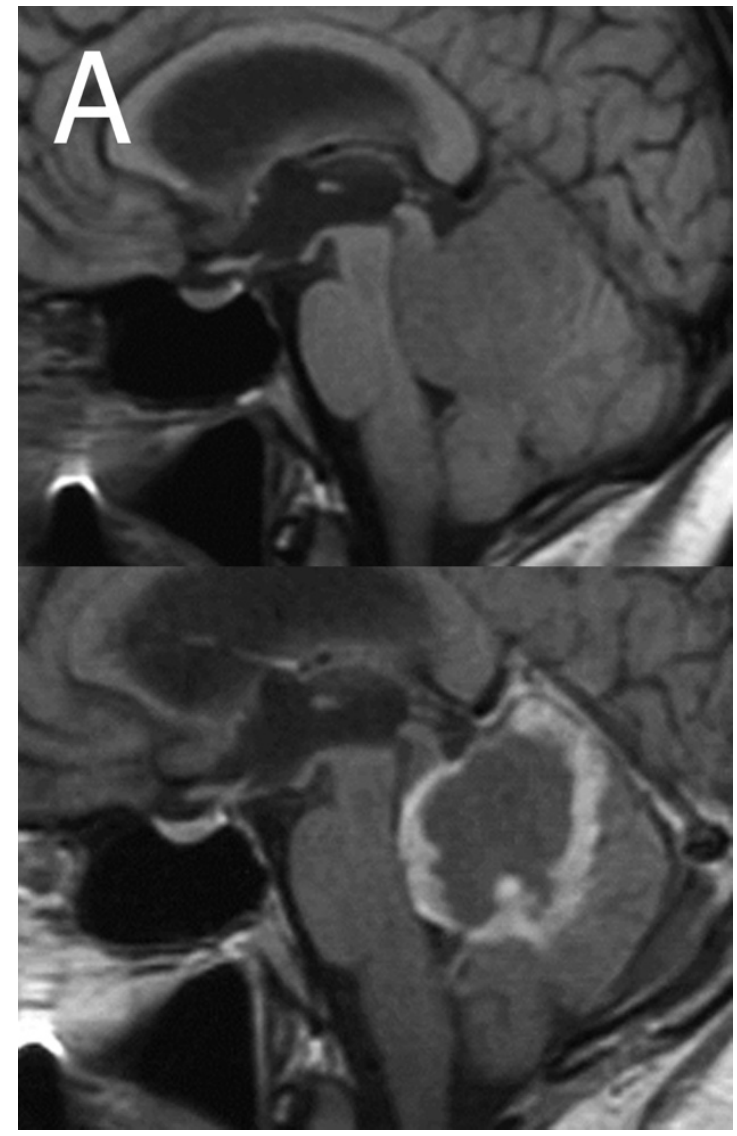

Figura 13s. T1WI sin y con gadolinio. Plano sagital. Masa con captación anular de contraste, centrada en fosa posterior y que distorsiona ligeramente el dorso del puente. Paciente VIH con cuadro brusco de inestabilidad, cefalea y desviación en la marcha. Linfoma cerebral primario. 


\section{METÁSTASIS}

Las metástasis siempre deben entrar en el diagnóstico diferencial de tumoraciones ocupantes de espacio en el sistema nervioso central, principalmente cuando se observan varias. Son numerosos los artículos que hacen referencia a metástasis localizadas en el APC [11, 15, 37, 40, 41] (Figura 13b).

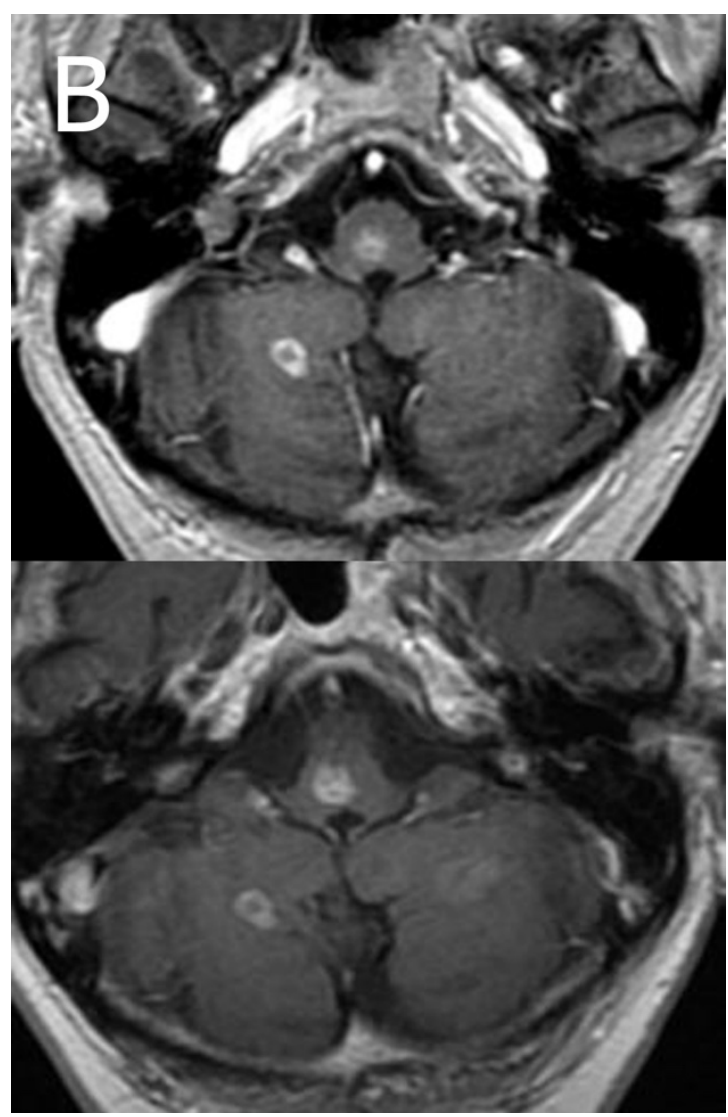

Figura 13b. T1WI con contraste endovenoso Cuadro evolutivo de inestabilidad en la marcha. Metástasis cerebrales en paciente con carcinoma microcítico de pulmón.

\section{HEMANGIOBLASTOMA}

Suponen aproximadamente el 1 al $2 \%$ de los tumores intracraneal y el 7 al $8 \%$ de los tumores de la fosa posterior [42]. El 75\% son esporádicos y el 25\% aparece en la enfermedad de Von Hippel-Lindau [14]. Se localizan más frecuentemente en el cerebelo, seguido de la médula espinal y del troncoencéfalo. Generalmente se manifiestan con cefaleas y náuseas, secundarias al aumento de la presión intracraneal, o con ataxia cerebelosa, siendo las alteraciones auditivas un síntoma poco frecuente [42]. Se suele apreciar una gran masa quística, homogénea, bien delimitada, con un pequeño nódulo mural hipervascular, aunque también puede aparecer como una masa sólida sin componente quístico. El nódulo es hipointenso en T1WI e hiperintenso en T2WI, con intenso realce tras la administración de contraste. Debido a su hipervascularización es posible apreciar vacíos de flujo en la periferia de la masa. Cuando están presentes los quistes suelen tener bordes bien definidos, homogéneos y con una intensidad de señal similar al LCR. Normalmente no presentan el edema o éste es mínimo [11].

\section{ESCLEROSIS TUBEROSA}

La esclerosis tuberosa es un síndrome multisistémico congénito. La mutación en los genes supresores de tumores de la esclerosis tuberosa produce una diferenciación y proliferación celular anormal lo que condiciona la aparición de hamartomas corticales o subcorticales, nódulos subependimarios y astrocitomas de células gigantes en el sistema nervioso central [14, 43]. Las manifestaciones clínicas neurológicas incluyen la epilepsia y deterioro cognitivo [43].

\section{MELANOMA LEPTOMENÍNGEO}

Los melanocitos están presentes en las leptomeninges intracraneales. Pueden dar lugar a tumores benignos (melanocitoma meníngeo) o malignos (melanoma maligno). Sin embargo, los melanomas malignos metastásicos son mucho más frecuentes que los tumores primarios melanocíticos [11]. Se han publicado casos esporádicos a nivel del APC $[44,45]$. Puede ser confundido con otras tumoraciones melanocíticas, como el schwannoma melanocítico o el meningioma melanocítico [46].

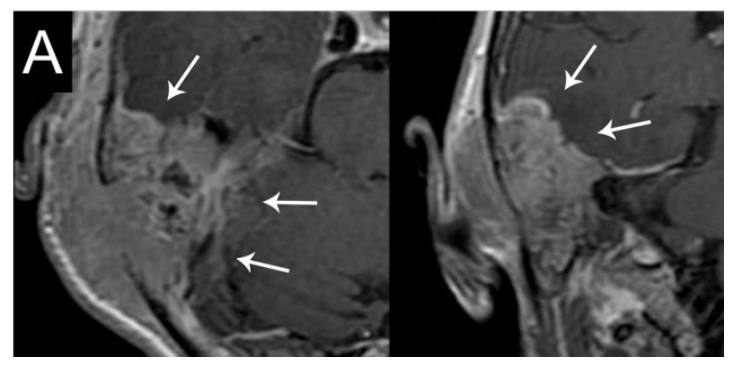

Figura 14a. T1WI + C. Planos axial y coronal. Realce heterogéneo. Se extiende infiltrando conductos semicirculares posterior y lateral, la caja timpánica, y conformando masa extraaxial. Melanoma leptomeníngeo.

En la RM se aprecia una intensidad de señal que varía en proporción a la cantidad de melanina. Por lo tanto, los tumores melanocíticos son isointensos o hiperintensos respecto al tejido adyacente normal del cerebro en secuencias potenciadas en T1 e hipo 
o isointensos en T2WI. Realzan tras la administración de contraste [11] (Figura 14a).

\section{LIPOMA}

Son malformaciones congénitas infrecuentes que surgen de la diferenciación anormal de la meninge primitiva [11]. A menudo son asintomáticos [47]. Es característica la alta intensidad de señal en T1 de manera homogénea, y la ausencia de señal en secuencias de supresión grasa. No realza tras la administración de contraste [11].

\section{GLIOMA TRONCOENCEFÁLICO}

Los gliomas del troncoencéfalo pueden manifestarse como una expansión asimétrica ocupando el APC, pudiendo confundirse con un neuroma vestibular. En la RM se aprecian como masas exofíticas hipointensas en T1 e hiperintensas en T2, con edema adyacente [11] (Figura 14b).

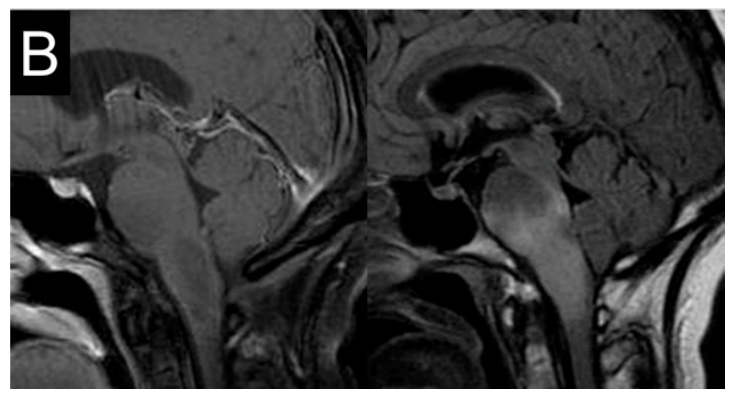

Figura 14b. Secuencias potenciadas en T1 con gadolinio, y T2 FLAIR en el plano sagital. Efecto de masa en bulbo y tercio inferior de la protuberancia con edema difuso traducido por hiperseñal, y sin realce tras contraste. Glioma troncoencefálico.

\section{OTROS TUMORES}

Más extraña es la ocupación e invasión secundaria del ángulo pontocerebeloso por tumores extracraneales, como en el caso que presentamos de carcinoma epidermoide auricular (Figura 14c).

En nuestra revisión también encontramos un caso asociado a enfermedad de Von Hippel-Lindau (EVHL) de adenocarcinoma papilar del saco endolinfático (TSEL). Los TSEL son tumores de crecimiento lento, pero localmente invasivos del hueso temporal de presentación aislada o en asociación a EVHL en un $15 \%$ de los casos. Clínicamente debutan con un síndrome de Ménière derivado de la compresión sobre el conducto endolinfático o con pérdida de audición, que suele ser brusca e irreversible. En imagen RM pueden presentar intensidad de señal alta o heterogénea por la presencia de productos hemáticos o proteicos [11] (Figura 15).

\section{PATOLOGÍA MALFORMATIVA E INFLAMATORIA ABSCESO}

Es raro que una tumoración ocupante de espacio a nivel del APC sea un absceso, pero existen varios casos registrados en la literatura [48-50]. Otras tumoraciones inflamatorias que pueden invadir el APC son la aracnoiditis y los tuberculomas que se extienden desde la protuberancia. Los abscesos crónicos también se pueden situar en el APC y son difíciles de distinguir de otros tumores en la misma ubicación $[48,50]$. Normalmente se aprecia una masa mal definida mixta, hipo o hiperintensa en secuencias potenciadas en T1 e hiperintensa en $\mathrm{T} 2 \mathrm{WI}$, con un patrón de realce anular muy típico, aunque inespecífico [14].

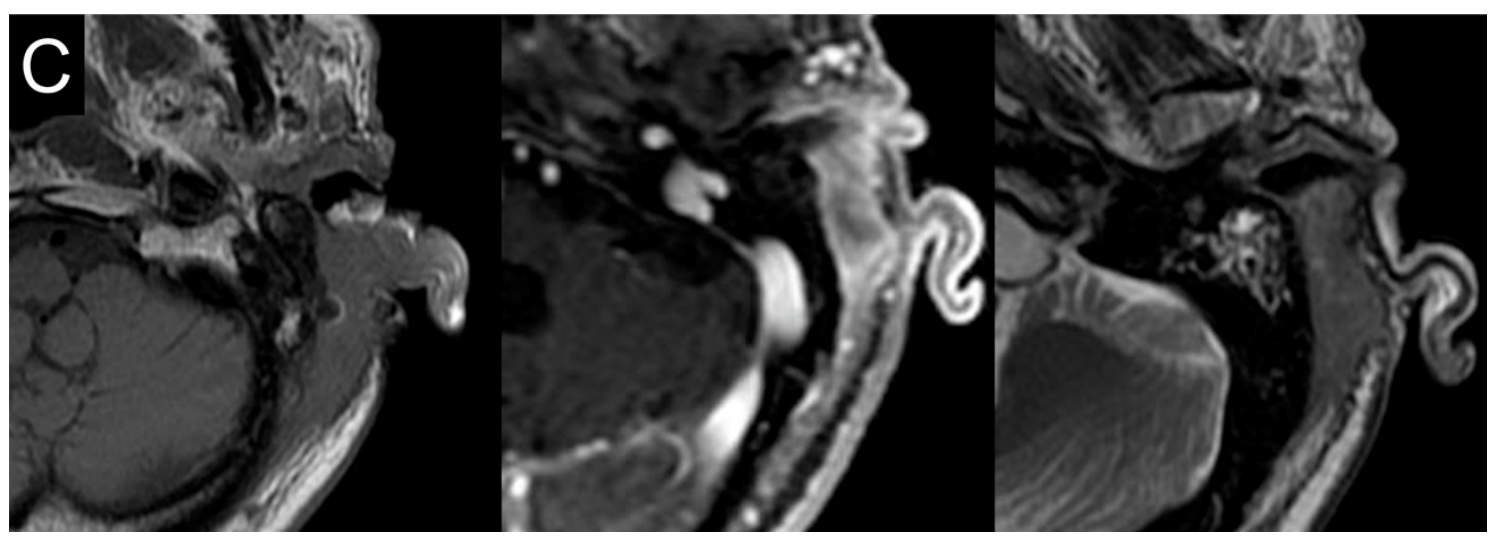

Figura 14c. Secuencias potenciadas en T1 sin y con gadolinio, y T2 en el plano axial. Carcinoma epidermoide auricular, con extensión a conducto auditivo externo, que asocia inestabilidad. Cúmulos de secreciones a nivel mastoideo. 


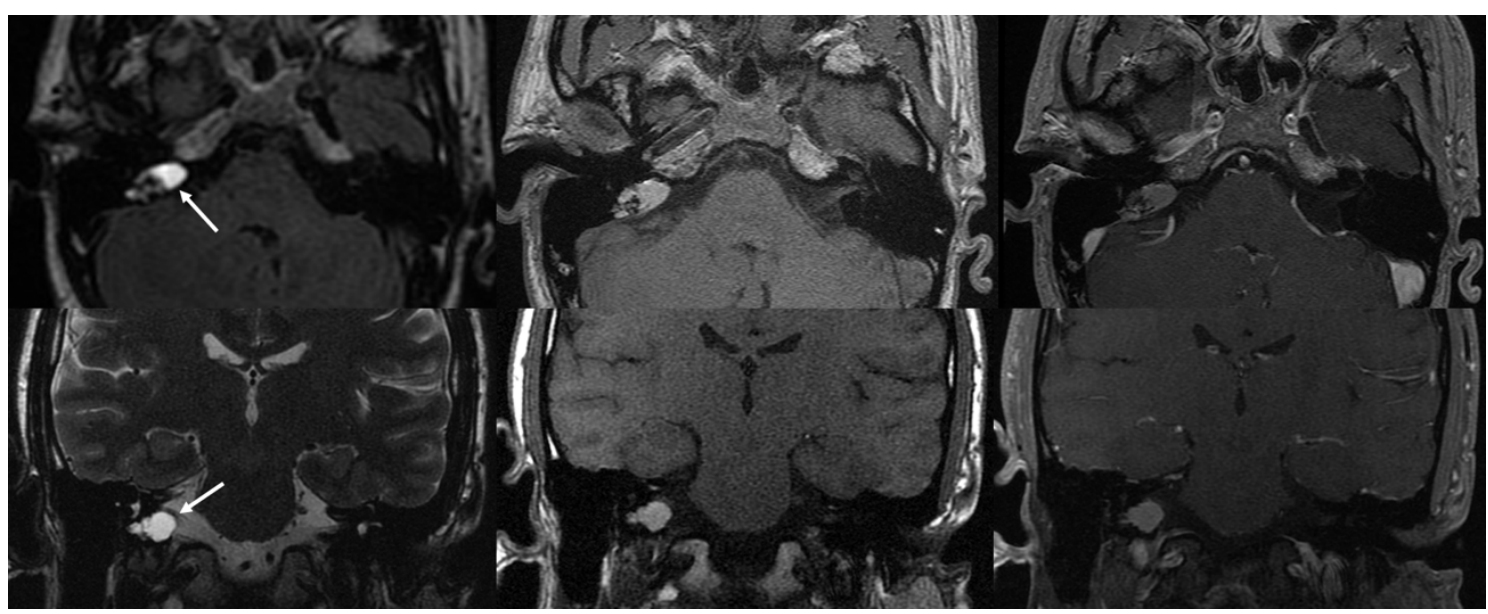

Figura 15. Tumor del saco endolinfático. Arriba cortes axiales; T2FLAIRWI, T1WI y T1WI + C. Abajo cortes coronales $\mathrm{T} 2 \mathrm{WI}$, T1WI y T1WI + C. Vértigo rotatorio y sordera unilateral. Masa heterogénea con predominio de hiperseñal en todas las secuencias de pulso, por presencia de proteínas debidas a productos de degradación de la hemoglobina debido a sangrados evolutivos. No realce significativo.

MALFORMACIÓN DE ARNOLD-CHIARI

En raras ocasiones una malformación de Arnold-Chiari causa clínica de hipoacusia o vértigo; algunos autores creen que es debido al efecto de «estiramiento» del VIII PC $[8,51]$. Las imágenes de RM sagitales muestran con claridad las amígdalas cerebelosas descendidas $[14,51]$.

\section{SÍNDROME DE SJÖGREN}

Es una enfermedad autoinmune que puede ser primaria o secundaria a otras enfermedades del tejido conectivo. Se caracteriza por la infiltración linfocítica y la destrucción de las glándulas salivales y lacrimales que conducen a la xerostomía y xeroftalmía, puede tener manifestaciones extraglandulares [52] La prevalencia de la afectación del sistema nervioso central y las alteraciones en RM en el síndrome de Sjögren primario son controvertidas [53]. Las manifestaciones más graves recuerdan a la esclerosis múltiple (EM), aunque normalmente los hallazgos de la RM sugieren discretos daños del tejido cerebral, apreciando pequeñas tumoraciones en la sustancia blanca, que son inespecíficas pues pueden confundirse con tumoraciones asociadas a la edad o factores de riesgo cerebrovascular, como la hipertensión. Son especialmente útiles las secuencias potenciadas en T2FSE y en T2FLAIR [54].

\section{MENINGITIS}

La meningitis bacteriana es una causa de pérdida profunda de la audición bilateral hasta en un $4 \%$ de los afectados. Probablemente es el resultado de la propagación de la infección al oído interno a través del acueducto coclear y se produce en una fase pre$\mathrm{coz}$ de la meningitis. La laberintitis consiguiente se cree que es la responsable de la pérdida auditiva neurosensorial [55].

Los hallazgos de imagen son inespecíficos, pudiendo apreciar un exudado isointenso en $\mathrm{T} 1 \mathrm{Wl}$ e hiperintenso en $\mathrm{T} 2 \mathrm{Wl}$, presentando realce tras la administración de contraste [14] (Figura 16).

\section{NEUROSARCOIDOSIS}

Puede manifestarse de varias formas: meníngea, parenquimatosa o ventricular [56].

El tipo meníngeo puede aparecer en un patrón difuso similar a una placa o, más focalmente, como una discreta masa, pudiendo incluso simular un meningioma del APC [57]. En nuestro ejemplo se manifestó como múltiples lesiones en cerebelo y tronco encéfalo hiperintensas en T2, apreciando realce leptomeníngeo tras la administración de contraste (Figura 17).

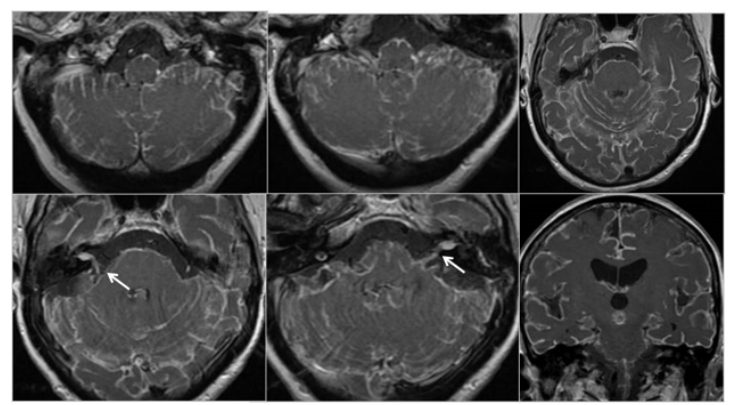

Figura 16. Meningitis bacteriana. Secuencia potenciada en T1 tras gadolinio. Captación meníngea y de ambos CAls. 


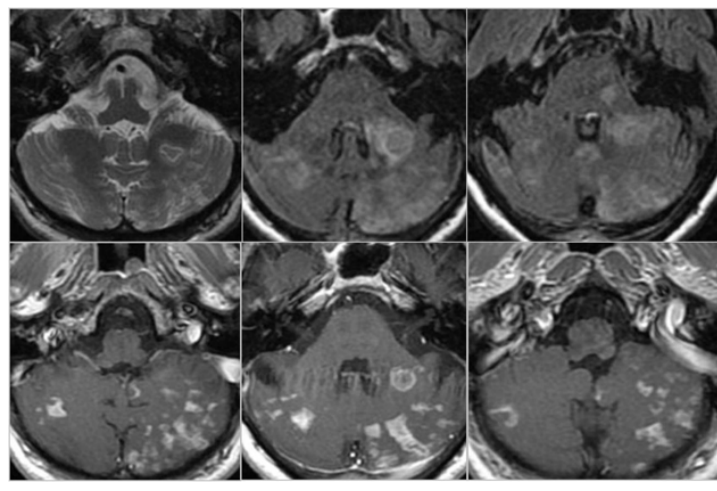

Figura 17. Imágenes superiores potenciadas en T2 y T2FLAIR, e inferiores T1WI tras contraste. Neurosarcoidosis. Paciente con sarcoidosis sistémica, que presenta cuadro vertiginoso mal definido, con mareo e inestabilidad. Zonas parcheadas de edema poco definidas y geográficas en espacio subaracnoideo y de aspecto más nodular en el pedúnculo cerebeloso medio izquierdo con realce serpinginoso tras contraste.

\section{OTRAS ALTERACIONES}

Existen casos recogidos de aplasia bilateral del canal semicircular posterior cuya clínica principal fue la presencia de vértigo posicional paroxístico atípico [58].

\section{CONCLUSIONES}

El estudio protocolario por RM en la hipoacusia y síndrome vertiginoso constituye uno de los motivos de consulta radiológica más frecuentes. Si bien los hallazgos patológicos son poco usuales y en muchos casos con poca implicación en el tratamiento sintomático, en un porcentaje significativo la detección de ciertas entidades resulta clave en el manejo, para lo cual la RM continúa siendo una herramienta imprescindible.

\section{BIBLIOGRAFÍA}

1. Som PM, Curtin HD. Head and neck imaging. 3rd ed. St. Louis: Mosby; 1996.

2. Sirikci A, Bayazit Y, Ozer E, Ozkur A, 13 Adaletli I, Cuce MA, et al. Magnetic resonance imaging based classification of anatomic relationship between the cochleovestibular nerve and anterior inferior cerebellar artery in patients with non-specific neuro-otologic symptoms. Surg Radiol Anat. 2005;27(6):531-5.
3. Gultekin S, Celik H, Akpek S, Oner Y, Gumus T, Tokgoz N. Vascular loops at the cerebellopontine angle: is there a correlation with tinnitus? Am J Neuroradiol. 2008;29(9):1746-9.

4. Caldemeyer KS, Mathews VP, Azzarelli B, Smith RR. The jugular foramen: a review of anatomy, masses, and imaging characteristics. 1997;17(5):1123-39.

5. Filipovic B, Gjuric M, Hat J, Gluncic I. High mega jugular bulb presenting with facial nerve palsy and severe headache. Skull base 2010;20(6):465-8.

6. Presutti L, Laudadio P. Jugular bulb diverticula. J Otorhinolaryngol Relat Spec. 1991;53(1):57-60.

7. Stern J, Goldenberg M. Jugular bulb diverticula in medial petrous bone. Am J Roentgenol. 1980;134(5):959-61.

8. Weissman JL, Hirsch BE. Imaging of tinnitus: a review. Radiology. 2000;216(2):342-9.

9. Harnsberger HR. Head and neck imaging. Chicago: Year Book Medical Publishers; 1990. xvi, 547 pp.

10. Press GA, Hesselink JR. MR imaging of cerebellopontine angle and internal auditory canal lesions at $1.5 \mathrm{~T}$. Am J Roentgenol. 1988;150(6):1371-81.

11. Bonneville F, Sarrazin JL, Marsot-Dupuch K, Iffenecker C, Cordoliani YS, Doyon D, et al. Unusual lesions of the cerebellopontine angle: a segmental approach. Radiographics. 2001;21(2):419-38.

12. Camacho DL, Smith JK, Grimme JD, Keyserling HF, Castillo M. Atypical MR imaging perfusion in developmental venous anomalies. Am $\mathrm{J}$ Neuroradiol. 2004;25(9):1549-52.

Santucci GM, Leach JL, Ying J, Leach SD, Tomsick TA. Brain parenchymal signal abnormalities associated with developmental venous anomalies: detailed MR imaging assessment. Am J Neuroradiol. 2008;29(7):1317-23.

14. Osborn AG. Expertddx. Brain and spine. 1st ed. Salt Lake City, Utah: Amirsys; 2009. 
15. Yun TJ, Na DG, Kwon BJ, Rho HG, Park SH, 25. Suh YL, et al. A T1 hyperintense perilesional signal aids in the differentiation of a cavernous angioma from other hemorrhagic masses. American J Neuroradiol. 2008;29(3):494-500.

16. Jinhu Y, Jianping D, Xin L, Yuanli Z. Dynamic 26. enhancement features of cavernous sinus cavernous hemangiomas on conventional contrast-enhanced MR imaging. Am J Neuroradiol. 2008;29(3):577-81.

17. Kwon BJ, Han MH, Kang HS, Chang KH. MR imaging findings of intracranial dural arteriovenous fistulas: relations with venous drainage patterns. Am $\mathrm{J}$ Neuroradiol. 2005;26(10):2500-7.

18. Lee SK, Willinsky RA, Montanera W, terBrugge $K G$. MR imaging of dural arteriovenous fistulas draining into cerebellar cortical veins. Am J Neuroradiol. 2003;24(8):1602-6.

19. Lapayowker MS, Liebman EP, Ronis ML, Safer JN. Presentation of the internal carotid artery as a tumor of the middle ear. Radiology. 1971;98(2):293-7.

20. Saatci I, Cekirge HS, Ciceri EF, Mawad ME, Pamuk AG, Besim A. CT and MR imaging findings and their implications in the follow-up of patients with intracranial aneurysms treated with endosaccular occlusion with onyx. Am J Neuroradiol. 2003;24(4):567-78.

21. Tanaka A, Ueno Y, Nakayama Y, Takano K, Takebayashi S. Small chronic hemorrhages and ischemic lesions in association with spontaneous intracerebral hematomas. Stroke. 1999;30(8):1637-42.

22. Mas JL, Meder JF, Meary E, Bousser MG. Magnetic resonance imaging in lateral sinus hypoplasia and thrombosis. Stroke. 1990;21(9):1350-6.

23. Khan S, Cloud GC, Kerry S, Markus HS. Imaging of vertebral artery stenosis: a systematic review. J Neurol Neurosurg Psychiatry. 2007;78(11):1218-25.

24. Cho TH, Nighoghossian N, Tahon F, Nemoz C, Hermier $M$, Salkine $F$, et al. Brain stem diffusion-weighted imaging lesion score: a potential marker of outcome in acute basilar artery occlusion. Am J Neuroradiol. 2009;30(1):194-8.
Seitz RJ, Meisel S, Weller P, Junghans U, Wittsack HJ, Siebler M. Initial ischemic event: perfusion-weighted MR imaging and apparent diffusion coefficient for stroke evolution. Radiology. 2005;237(3):1020-8.

Kleihues P, Burger PC, Scheithauer BW. The new $\mathrm{WHO}$ classification of brain tumours. Brain Pathol. 1993;3(3):255-68.

27. Koral K, Kedzierski RM, Gimi B, Gomez A, Rollins NK. Subependymoma of the cerebellopontine angle and prepontine cistern in a 15-year-old adolescent boy. Am J Neuroradiol. 2008;29(1):190-1.

28. Koeller KK, Rushing EJ. From the archives of the AFIP: medulloblastoma: a comprehensive review with radiologic-pathologic correlation. Radiographics. 2003;23(6):1613-37.

29. Park SY, Kim JH, Kim KT, Kim YJ, Kim TH, Hwang $\mathrm{K}$, et al. A case of medullomyoblastoma of cerebellopontine angle mimicking acoustic neuroma. Yonsei Med J. 2004;45(4):719-22.

30. Thurnher MM. 2007 World Health Organization classification of tumours of the central nervous system. Cancer imaging. 2009;9 Spec No A:S1-3.

31. Gelabert-Gonzalez M. Quistes aracnoideos intracraneales. Revista de neurologia. 2004;39(12):1161-6.

32. Martinez-Lage JF, Ramos J, Puche A, Poza M. Extradural dermoid tumours of the posterior fossa. Arch Dis Child. 1997;77(5):427-30.

33. Oliver B TP, Quer M, Colomo L. Granulomas de colesterol de punta de peñasco. A propósito de dos casos. Neurocirugia. 1999;10(04):31323.

34. Castillo Lario MC LDR, Pina Leita I. Radiological diagnosis of cholesterol granulomas at the petrous apex. Acta Otorrinolaringol Esp. 2007 58(6):280.

35. Kallmes DF, Provenzale JM, Cloft HJ, McClendon RE. Typical and atypical MR imaging features of intracranial epidermoid tumors. Am J Roentgenol. 1997;169(3):883-7.

36. Shihada R, Brodsky A, Luntz M. Giant cholesteatoma of the temporal bone. Isr Med Assoc J. 2006;8(10):718-9. 
37. Fortnum $\mathrm{H}$, O'Neill $\mathrm{C}$, Taylor $\mathrm{R}$, Lenthall $\mathrm{R}, 48$. Nikolopoulos $T$, Lightfoot $G$, et al. The role of magnetic resonance imaging in the identification of suspected acoustic neuroma: a systematic review of clinical and cost effectiveness and natural history. Health Technol Assess. 2009;13(18):iii-iv, ix-xi, 1-154.

38. Tsukamoto $\mathrm{H}$, Hikita $\mathrm{T}$, Takaki $\mathrm{T}$. Cerebellopontine angle meningioma associated with cranial accessory nerve neurinoma--case report. Neurol Med Chir. 1994;34(4):225-9.

39. Wang YT, Su HH, Hou Y, Chu ST, Lai PH, Tseng $\mathrm{HH}$, et al. Diffuse large B-cell lymphoma of the cerebellopontine angle in a patient with sudden hearing loss and facial palsy. J Chin Med Assoc. 2007;70(7):294-7.

40. Godhamgaonkar $\bigvee$, Domjan J. "Why have I got a 'dead ear', doctor"? $\mathrm{Br} \mathrm{J}$ Radiol. 2009;82(982):877-9.

41. Hamid B, Harris C, Spiess J. Metastatic adenocarcinoma in the cerebellopontine angle mimicking facial nerve Schwannoma. Am J Clin Oncol. 2007;30(5):566-7.

42. Amano T, Tokunaga S, Shono T, Mizoguchi M, Matsumoto K, Yoshida F, et al. Cerebellar hemangioblastoma manifesting as hearing disturbance. Neurol Med Chir. 2009;49(9):41820.

43. Kalantari BN, Salamon N. Neuroimaging of tuberous sclerosis: spectrum of pathologic findings and frontiers in imaging. $A m ~ J$ Roentgenol. 2008;190(5):W304-9.

44. Gupta A, Ahmad FU, Sharma MC, Garg A, Mehta VS. Cerebellopontine angle meningeal melanocytoma: a rare tumor in an uncommon location. Case report. J Neurosurg. 2007;106(6):1094-7.

45. Hamasaki O, Nakahara T, Sakamoto S, Kutsuna M, Sakoda K. Intracranial meningeal melanocytoma. Neurol Med Chir 2002;42(11):504-9.

46. Gonzalez-Tortosa J, Ferri-Niguez B, Ros de San Pedro J. Cerebellopontine angle meningeal melanocytoma: a benign tumor? Neurocirugia (Astur). 2009;20(4):372-9; discussion 379-80.

47. Karadeli E, Ulu E. Inner ear lipoma. Diagn Interv Radiol. 2010;16(1):24-6.
Srinivasan V, Anandacoomaraswamy KS, Atlas MD. Sterile abscess mimicking recurrent tumour in the cerebellopontine angle. J Laryngol Otol. 2002;116(5):379-81.

49. Bekar A, Kocaeli H, Yilmaz E, Dogan S. Trigeminal neuralgia caused by a pontine abscess: case report. Neurosurgery. 2004;55(6):1434.

50. Tolosa E. Abscesses of the cerebellopontine angle. J Neurosurg. 1961;18:113-4.

51. Weissman JL. Hearing loss. Radiology. 1996;199(3):593-611.

52. Garcia-Carrasco M, Ramos-Casals M, Rosas J, Pallares L, Calvo-Alen J, Cervera R, et al. Primary Sjogren syndrome: clinical and immunologic disease patterns in a cohort of 400 patients. Medicine. 2002;81(4):270-80.

53. Sanahuja J, Ordonez-Palau S, Begue R, Brieva L, Boquet D. Primary Sjogren Syndrome with tumefactive central nervous system involvement. Am J Neuroradiol. 2008;29(10):1878-9.

54. Morgen K, McFarland HF, Pillemer SR. Central nervous system disease in primary Sjogrens syndrome: the role of magnetic resonance imaging. Semin Arthritis Rheum. 2004;34(3):623-30.

55. Beijen J, Casselman J, Joosten F, Stover T, Aschendorff A, Zarowski A, et al. Magnetic resonance imaging in patients with meningitis induced hearing loss. Eur Arch Otorhinolaryngol. 2009;266(8):1229-36.

56. Lexa FJ, Grossman RI. MR of sarcoidosis in the head and spine: spectrum of manifestations and radiographic response to steroid therapy. Am J Neuroradiol. 1994;15(5):973-82.

57. Lipper $\mathrm{MH}, \quad$ Goldstein JM. Neurosarcoidosis mimicking a cerebellopontine angle meningioma. AJR Am J Roentgenol. 1998;171(1):275-6.

58. Walther LE, Nath V, Krombach GA, Di Martino E. Bilateral posterior semicircular canal aplasia and atypical paroxysmal positional vertigo: a case report. Acta Otorhinolaryngol Ital. 2008;28(2):79-82. 